\title{
Abdominal trunk muscle weakness and its association with chronic low back pain and risk of falling in older women
}

Satoshi Kato* ${ }^{*}$, Hideki Murakami, Satoru Demura, Katsuhito Yoshioka, Kazuya Shinmura, Noriaki Yokogawa, Takashi Igarashi, Noritaka Yonezawa, Takaki Shimizu and Hiroyuki Tsuchiya

\begin{abstract}
Background: Previous studies have indicated that trunk muscle strength decreases with chronic low back pain, and is associated with poor balance, poor functional performance, and falls in older adults. Strengthening exercises for chronic low back pain are considered the most effective intervention to improve functional outcomes. We developed an innovative exercise device for abdominal trunk muscles that also measures muscle strength. The correlation between muscle weakness, as measured by our device, the presence of chronic low back pain, and decreased physical ability associated with a risk of falling were evaluated in older women.
\end{abstract}

Methods: Thirty-eight elderly women, who could walk without support during daily activities and attended our outpatient clinic for treatment of chronic low back pain, knee or hip arthritis, or osteoporosis, were included in this study. Anthropometric measurements were performed. Grip power and one-leg standing time with eyes open were measured, and abdominal trunk muscle strength was measured using our device. History of falling in the previous 12 months was noted. Subjects with chronic low back pain (visual analog scale score $\geq 20 \mathrm{~mm}$ ) for over 3 months were assigned to the low back pain group $(n=21)$. The remaining subjects formed the non-low back pain group $(n=17)$.

Results: Abdominal muscle strength of subjects in the low back pain group, and with history of falling, was significantly lower compared with that of subjects in the non-low back pain group, and in subjects without a history of falling, respectively. There was a moderate positive correlation between abdominal trunk muscle strength and one-leg standing time with eyes open.

Conclusion: We measured abdominal muscle strength in older women with chronic low back pain using our device, and it was significantly lower than that of those without chronic low back pain. Muscle weakness was associated with a history and risk of falling.

Keywords: Abdominal trunk muscle, Chronic low back pain, Innovative exercise device, Muscle strength measurement, Older women, Risk of falling

\footnotetext{
* Correspondence: skato323@gmail.com

Department of Orthopaedic Surgery, Graduate School of Medical Sciences,

Kanazawa University, 13-1 Takara-machi, Kanazawa 920-8641, Japan
}

(c) The Author(s). 2019 Open Access This article is distributed under the terms of the Creative Commons Attribution 4.0 International License (http://creativecommons.org/licenses/by/4.0/), which permits unrestricted use, distribution, and reproduction in any medium, provided you give appropriate credit to the original author(s) and the source, provide a link to the Creative Commons license, and indicate if changes were made. The Creative Commons Public Domain Dedication waiver (http://creativecommons.org/publicdomain/zero/1.0/) applies to the data made available in this article, unless otherwise stated. 


\section{Background}

Low back pain (LBP) is a major health problem with great economic and social costs [1]. It is estimated that approximately $80 \%$ of the adults have at least one experience of LBP in their lifetime $[2,3]$. LBP was found to be the most common type of chronic musculoskeletal pain according to a large-scale survey examining the prevalence and status of chronic musculoskeletal pain in Japan [4]. Trunk muscle weakness has been reported as a risk factor for LBP $[5,6]$. Exercise therapy is widely used as a treatment for chronic LBP (CLBP) [7-10]. Some systematic reviews demonstrated that muscle strengthening exercise had a beneficial effect over other interventions in the treatment of CLBP [10, 11]. A substantial proportion of elderly patients with severe CLBP cannot continue the prescribed exercise regimen due to a loss of flexibility and/or deformity in the spine or muscle weakness in the trunk and/or extremities $[12,13]$.

Locomotive syndrome is a condition of reduced mobility due to impairment of locomotive organs [14]. Progression of this syndrome results in limiting independence in carrying out activities of daily living. A decline in mobility results from one or more disorders of the locomotive structures, including bones, joints, muscles, and nerves [14]. These disorders correlate strongly with future disability, falling, and fractures [15, 16]. Thus, evaluation of physical function and intervention for musculoskeletal disorders are important to maintain quality of life in the elderly. Exercise intervention for locomotive syndrome is effective in improving physical performance, but because most patients are elderly people with significant degenerative diseases of the locomotor organs, caution should be employed when choosing the type and intensity of exercise [17].

We developed an innovative exercise device for the abdominal trunk muscles (Fig. 1: trunk muscle exercise device; Nippon Sigmax Co., Ltd., Shinjuku-ku, Tokyo, Japan) [18]. Using this device, subjects can perform strengthening exercises for the abdominal trunk muscles in a sitting position without the need for trunk movement, including movement of the lumbar spine. These exercises are therefore more easily accessible to patients with flexibility loss, deformity of the spine, or severe pain. The device also has a built-in system for measuring abdominal trunk muscle strength, which may reinforce adherence to an exercise program. Our previous studies demonstrated that the device was a reliable tool to measure abdominal trunk muscle strength, and strengthening exercise with the device increased the strength and activated the abdominals, diaphragm, and pelvicfloor muscles to stabilize the spine [19].

In this study, we measured abdominal trunk muscle strength using our device in older women. Our main aim of the study was to investigate the association between muscle weakness and the presence of CLBP. In addition, and as a secondary aim, we studied the relationship between muscle weakness and the risk of falling.

\section{Methods \\ Description of the device}

As previously described in detail [18], the device has an inflatable cuff and a built-in mechanical manometer to measure pressure. To take a measurement, the cuff placed around the subject's abdomen is inflated, and an adequate pressure (i.e., the baseline pressure: Fig. 2) is applied to the abdominal wall. Under the baseline pressure, the subject exerts the maximum force by contracting the abdominal muscles. The pressure in the cuff is elevated and reaches a peak (i.e., the peak pressure: Fig. 2). The manometer reports a pressure value that subtracts the baseline pressure from the peak pressure to provide the muscle-
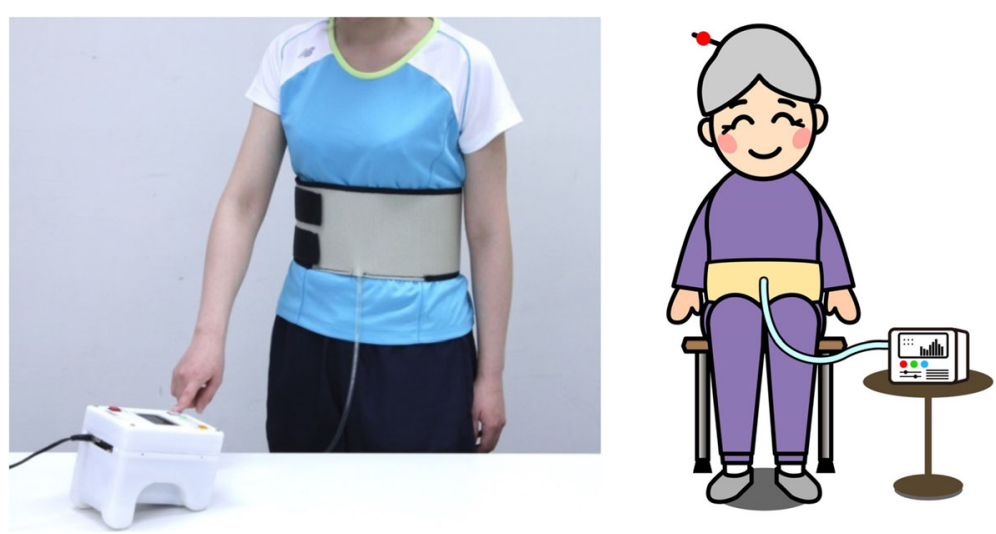

Fig. 1 Innovative exercise device for strengthening the abdominal trunk muscle The left image shows a photograph of the device and a subject wearing the inflatable cuff around the abdomen. The right image represents a device-equipped subject in seated position (the image is the authors' own work) 


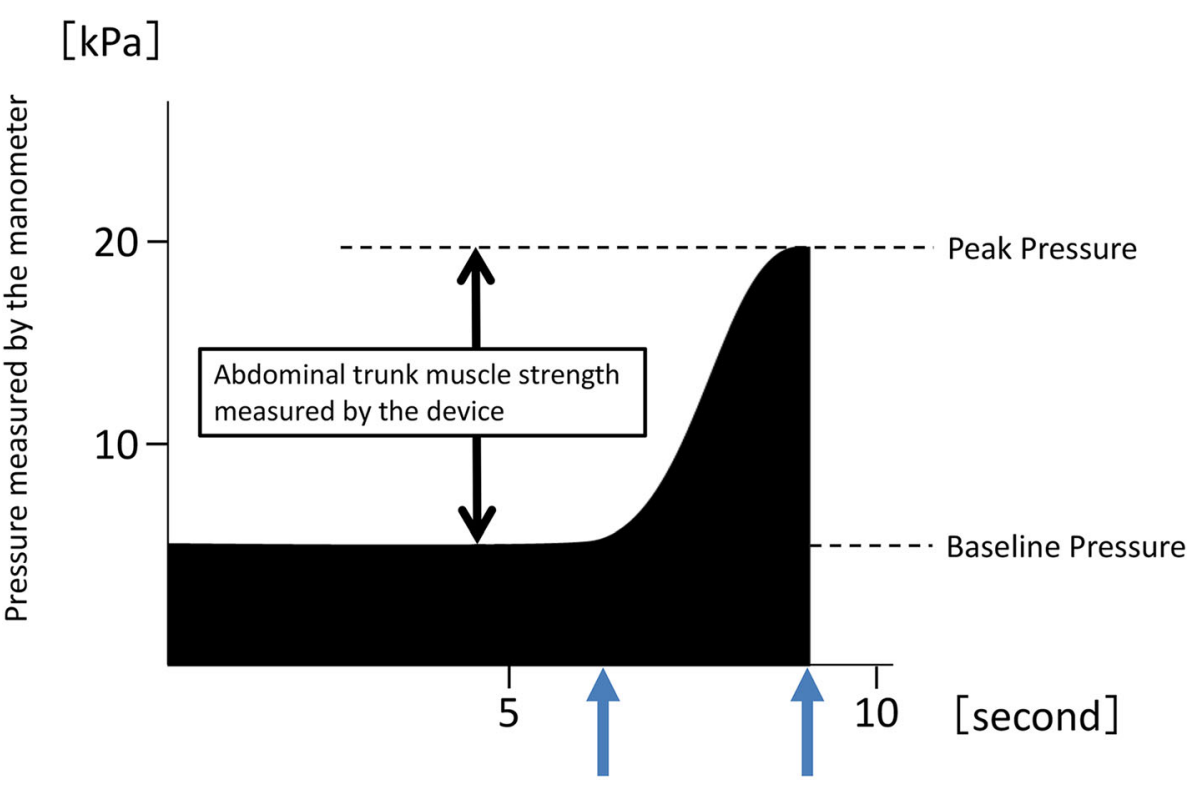

(A)

(B)

Fig. 2 Pressure value time course indicated by the mechanical manometer of the device during measurement of abdominal trunk muscle strength. a Indicates the time point when the subject's abdominal muscles begin to contract against the pressure. b Shows the reduction in pressure in the cuff after attainment of peak pressure

strength value. The muscle-strength value was defined in this study as the abdominal trunk muscle strength.

\section{Subjects}

Thirty-eight consecutive elderly women in their 70 s or 80 s who could walk without support (such as a T-cane or a walker) in their daily activities and agreed to participate in this study were recruited between April and December 2015. They regularly attended out institution as orthopedic outpatients for the treatment of CLBP, knee or hip arthritis, or osteoporosis. Patients who could not complete the following physical examinations conducted in the study due to musculoskeletal or medical disorders were excluded from the study (Table 1). We obtained anthropometric measurements including body height, body weight, body mass index, and girth. We measured each patient's grip power using a dynamometer, one-leg standing time with eyes open, and abdominal trunk muscle strength using our device. One-leg standing time with eyes open has been shown to be a good predictor of falls in the literature [20-22]. We obtained any history of falling in the previous 12 months and responses to the 25-Question Geriatric Locomotive Function Scale (GLFS-25), which is one of the assessment tools for locomotive syndrome [17]. Twenty-one of the subjects with CLBP for more than 3 months, and a visual analog scale (VAS) score for LBP of $\geq 20 \mathrm{~mm}$ were assigned to the LBP group. For the LBP group, we obtained responses to the Japanese Orthopaedic Association Back
Pain Evaluation Questionnaire (JOABPEQ). The JOABPEQ provides specific, yet multidimensional, outcome measures for patients with LBP, including dysfunctions and disabilities caused by the disease, and psychosocial problems resulting from such dysfunctions and

Table 1 Subject characteristics and exclusion criteria of the study

\section{Characteristic}

No. of subjects

38

Age (years), mean \pm SD [range]

$77.7 \pm 4.2[70-86]$

Height $(\mathrm{cm})$, mean $\pm \mathrm{SD}$ [range]

$148.1 \pm 6.0[137-160]$

Weight $(\mathrm{kg})$, mean \pm SD [range]

$50.5 \pm 7.5[35-67]$

Body-mass index $\left(\mathrm{kg} / \mathrm{cm}^{2}\right)$, mean $\pm \mathrm{SD} \quad 23.0 \pm 3.3$ [15.4-30.1] [range]

Girth $(\mathrm{cm})$, mean \pm SD

$79.7 \pm 11.2[58-110]$

Musculoskeletal disorders treated at the outpatient clinic (no. of subjects)

Chronic LBP (21), Knee (22) and hip (3) arthritis, and Osteoporosis (14)

Exclusion criteria of the study

- They did not agree to participate in this trial.

- They did not have the ability to walk without support during their daily activities.

- They could not complete physical examinations conducted in the trial due to their musculoskeletal or medical disorders.

- They had acute LBP or mild chronic LBP $(0 \mathrm{~mm}<$ VAS score for chronic LBP $<20 \mathrm{~mm}$ ).

$S D$ standard deviation, $L B P$ low back pain, VAS visual analog scale 
disabilities [23]. Seventeen of the subjects without LBP (VAS score $=0 \mathrm{~mm}$ ) were assigned to the non-LBP group. Subjects with acute LBP or mild CLBP $(0 \mathrm{~mm}<$ VAS score for CLBP $<20 \mathrm{~mm}$ ) were excluded from the study. Subjects whose one-leg standing time was shortened owing to their knee or hip pain were excluded from the study. Measurement of one-leg standing time with eyes open was performed once for each of the right and left legs, and with each measurement for a maximum time of $30 \mathrm{~s}$. Subjects were instructed to stand either wearing comfortable shoes or without shoes, with arms placed at their sides. We recorded the measurements with higher values.

\section{Statistical analysis}

All data are presented as means and standard deviations. The data were checked for normal distribution with the Shapiro-Wilk test and for homogeneity of the variances with the Levene test. Differences between two groups in continuous variables were examined using the Student $t$ test for parametric data and the Mann-Whitney $U$ test for nonparametric data. Fisher's exact test was used to determine any association between the presence of CLBP and a history of falling in the past 12 months. Multivariate logistic regression analyses were performed to determine significant factors associated with CLBP and falls. The Pearson correlation coefficient analysis was used to evaluate the correlations between the abdominal trunk muscle strength and age, anthropometric measurements, grip power, one-leg standing time, and GLFS-25 scores. In the LBP group, the Pearson correlation coefficient analysis was used to evaluate the correlations between abdominal trunk muscle strength and VAS scores, as well as the scores in various dimensions of the JOABPEQ. The level of statistical significance was set to 0.05. SPSS software version 19.0 for Windows
(SPSS Inc., Chicago, Illinois, USA) was used for all statistical analyses.

\section{Results}

None of the participants experienced pain or discomfort during the measurement of abdominal trunk muscle strength using our device, or during grip power measurement or the one-leg standing time with eyes open test. In the univariate analysis, there were no differences between the LBP and non-LBP groups with regards to age, anthropometric measurements, grip power, one-leg standing time, or history of falling (Table 2). However, abdominal trunk muscle strength as measured by our device was significantly lower in the LBP group than in the non-LBP group $(5.1 \pm 2.4 \mathrm{kPa}$ versus $7.1 \pm 3.2 \mathrm{kPa}$, $P<0.05$; Table 2). Furthermore, GLFS-25 scores were significantly higher in the LBP group (Table 2). The multivariate logistic regression analysis showed that abdominal trunk muscle strength $(P=0.03$; odds ratio, $0.71)$ and GLFS-25 scores $(P=0.03$; odds ratio, 1.10$)$ were independently associated with CLBP (Table 3).

Of 39 subjects, 10 had a history of falling in the past 12 months (fall group), while the remainder of the patients $(n=28)$ did not (non-fall group). In the univariate analysis, there were no significant differences between the fall and non-fall groups with regards to age, body height, body-mass index, girth, one-leg standing time, or GLFS-25 score (Table 4). However, abdominal trunk muscle strength as measured by our device, grip power, and body weight were significantly lower in the fall group (Table 4). The multivariate logistic regression analysis showed that abdominal trunk muscle strength $(P=$ 0.01 ; odds ratio, 0.45$)$ and body weight $(P=0.03$; odds ratio, 0.83 ) were independently associated with a history of falling in the previous 12 months (Table 5).

There was a moderate positive correlation between abdominal trunk muscle strength and one-leg standing

Table 2 Univariate analysis of characteristics between the LBP group and Non-LBP groups

\begin{tabular}{|c|c|c|c|}
\hline Characteristics & LBP group & Non-LBP group & $p$ value \\
\hline No. of patients & 21 & 17 & \\
\hline Age (years), mean $\pm \mathrm{SD}$ & $77.4 \pm 4.2$ & $78.1 \pm 4.4$ & 0.67 \\
\hline Height $(\mathrm{cm})$, mean \pm SD & $147.5 \pm 6.2$ & $148.8 \pm 5.7$ & 0.50 \\
\hline Weight $(\mathrm{kg})$, mean \pm SD & $50.7 \pm 7.8$ & $50.2 \pm 7.4$ & 0.85 \\
\hline Body-mass index $\left(\mathrm{kg} / \mathrm{cm}^{2}\right)$, mean $\pm \mathrm{SD}$ & $23.3 \pm 3.7$ & $22.7 \pm 2.9$ & 0.53 \\
\hline Girth $(\mathrm{cm})$, mean \pm SD & $81.7 \pm 11.6$ & $77.3 \pm 10.6$ & 0.24 \\
\hline Abdominal trunk muscle strength measured by the device $(\mathrm{kPa})$, mean $\pm \mathrm{SD}$ & $5.1 \pm 2.4$ & $7.1 \pm 3.2$ & 0.03 \\
\hline Grip power (kg), mean \pm SD & $17.5 \pm 4.0$ & $19.1 \pm 3.9$ & 0.23 \\
\hline One-leg standing time with eyes open (sec), mean \pm SD & $12.1 \pm 7.7$ & $16.8 \pm 10.2$ & 0.11 \\
\hline GLFS-25 Scores, mean \pm SD & $21.9 \pm 12.2$ & $13.4 \pm 10.2$ & 0.03 \\
\hline History of falling in the previous 12 months, No. (\%) & $6(28.6 \%)$ & $4(23.5 \%)$ & 0.51 \\
\hline
\end{tabular}


Table 3 Multivariate logistic regression analysis of factors correlated with chronic LBP

\begin{tabular}{llll}
\hline Factors & $\mathrm{OR}$ & $95 \% \mathrm{Cl}$ & $p$ value \\
\hline Abdominal trunk muscle strength $(\mathrm{kPa})$ & 0.707 & $0.515-0.971$ & 0.032 \\
GLFS-25 Scores & 1.098 & $1.009-1.194$ & 0.030 \\
\hline
\end{tabular}

LBP low back pain, OR odds ratio, Cl confidence interval, GLFS-25 the 25Question Geriatric Locomotive Function Scale

time with eyes open $\left(r_{p}=0.44, P<0.01\right.$; Table 6, Fig. 3). However, there was no correlation between abdominal trunk muscle strength and other items evaluated (Table 6). There was no correlation between abdominal trunk muscle strength and VAS score for CLBP, or scores in the various dimensions of the JOABPEQ in the LBP group. The correlation between muscle strength and pain-related disorder scores on the JOABPEQ was nearly significant $\left(\mathrm{r}_{\mathrm{p}}=0.40, P=0.07\right.$; Table 7$)$.

\section{Discussion}

This study sought to examine whether abdominal trunk muscle strength, measured using a novel device, was associated with CLBP or risk of falling in elderly women. Our results demonstrated that abdominal muscle strength of subjects with CLBP was significantly lower than that of subjects without CLBP. Furthermore, muscle strength weakness was associated with a history and risk of falling. A history of falling in the past 12 months and one-leg standing time with eyes open have been reported to be significant risk factors for falling in the elderly $[22,24,25]$. Locomotive syndrome assessment scores were higher in subjects with CLBP in our study.

Several studies have indicated that patients with LBP have significantly lower abdominal muscle strength than asymptomatic patients [26-28]. A previous study demonstrated that muscle strength, as measured using our exercise device, was correlated with trunk flexor strength, including the abdominal rectus and abdominal
Table 5 Multivariate logistic regression analysis of factors correlated with a history of falling in the previous 12 months

\begin{tabular}{llll}
\hline Factors & OR & $95 \% \mathrm{Cl}$ & $p$ value \\
\hline Weight $(\mathrm{kg})$ & 0.833 & $0.707-0.982$ & 0.029 \\
Abdominal trunk muscle strength $(\mathrm{kPa})$ & 0.446 & $0.235-0.846$ & 0.014 \\
\hline
\end{tabular}

$O R$ odds ratio, $\mathrm{Cl}$ confidence interval

oblique located in the anterolateral aspect of the abdomen [18]. The diaphragm, abdominal rectus, external and internal oblique, transverse abdominal, and levator ani muscles were significantly activated while strengthening using the device [19].

The abdominal core can be described as a muscular box with the abdominals in the front and sides, paraspinals in the back, diaphragm as the roof, and pelvic floor muscles as the bottom [29]. The abdominal contraction maneuver under a pressure produced by the device is like abdominal bracing and creates the coordinated contraction of the deep and superficial core muscles at the anterolateral aspect, the top and bottom of the "muscular box" of the core [19]. The strength of abdominal trunk muscles, as measured by the device, is generated by the contraction of these core muscles to increase intra-abdominal pressure and spinal stability. The results of this study indicated that abdominal trunk muscle weakness measured by the device was associated with CLBP in older women. The muscle strengthening exercises undertaken with the device may be a viable option for the treatment of patients with CLBP, especially in older adults with lowered physical ability.

One systematic review reported that weak trunk muscle strength was correlated with poor balance and functional performance, and more falls in older adults [30]. Granacher et al. demonstrated that core instability strength training mitigated trunk muscle strength, dynamic balance, and functional mobility in older adults [31]. Consistent with these studies, our results have

Table 4 Univariate analysis of characteristics between the Fall and non-Fall groups

\begin{tabular}{|c|c|c|c|}
\hline Characteristics & Fall group & Non-Fall group & $p$ value \\
\hline No. of patients & 10 & 28 & \\
\hline Age (years), mean $\pm S D$ & $79.5 \pm 4.1$ & $77.1 \pm 4.2$ & 0.12 \\
\hline Height $(\mathrm{cm})$, mean $\pm \mathrm{SD}$ & $146.2 \pm 6.6$ & $148.8 \pm 5.7$ & 0.25 \\
\hline Weight $(\mathrm{kg})$, mean $\pm S D$ & $46.4 \pm 8.4$ & $52.0 \pm 6.8$ & 0.04 \\
\hline Body-mass index $\left(\mathrm{kg} / \mathrm{cm}^{2}\right)$, mean $\pm \mathrm{SD}$ & $21.7 \pm 3.5$ & $23.5 \pm 3.1$ & 0.13 \\
\hline Girth $(\mathrm{cm})$, mean \pm SD & $77.6 \pm 12.0$ & $80.5 \pm 11.1$ & 0.50 \\
\hline Abdominal trunk muscle strength measured by the device $(\mathrm{kPa})$, mean $\pm \mathrm{SD}$ & $3.8 \pm 1.7$ & $6.8 \pm 2.9$ & $<0.01$ \\
\hline Grip power (kg), mean \pm SD & $15.4 \pm 2.6$ & $19.3 \pm 3.9$ & $<0.01$ \\
\hline One-leg standing time with eyes open (sec), mean \pm SD & $12.6 \pm 9.6$ & $14.8 \pm 9.0$ & 0.52 \\
\hline GLFS-25 Scores, mean \pm SD & $20.0 \pm 15.6$ & $17.4 \pm 10.7$ & 0.57 \\
\hline CLBP for $\geq 3$ months (VAS $\geq 20$ ), No. (\%) & $6(60.0 \%)$ & $15(53.6 \%)$ & 0.51 \\
\hline
\end{tabular}

SD standard deviation, GLFS-25 the 25-Question Geriatric Locomotive Function Scale, CLBP chronic low back pain, VAS visual analog scale 
Table 6 Correlation with the Abdominal trunk muscle strength measured by the device in the all 38 participants

\begin{tabular}{llll}
\hline & Mean \pm SD & \multicolumn{2}{l}{ Correlations with abdominal trunk muscle strength } \\
\cline { 3 - 4 } & & $R_{p}$ value & $P$ value \\
\hline Abdominal trunk muscle strength measured by the device $(\mathrm{kPa})$ & $6.0 \pm 4.0$ & - & - \\
Age (years) & $77.7 \pm 4.2$ & -0.23 & 0.16 \\
Height (cm) & $148.1 \pm 4.8$ & -0.11 & 0.51 \\
Weight (kg) & $50.0 \pm 7.5$ & -0.12 & 0.48 \\
Body-mass index (kg/ $\mathrm{cm}^{2}$ ) & $23.0 \pm 3.3$ & -0.05 & 0.77 \\
Girth (cm) & $84.4 \pm 6.3$ & -0.23 & 0.17 \\
Grip power (kg) & $79.7 \pm 11.2$ & 0.25 & 0.13 \\
One-leg standing time with eyes open (sec) & $14.2 \pm 9.1$ & 0.44 & $<0.01$ \\
GLFS-25 Scores & $18.1 \pm 12.0$ & -0.01 & 0.95
\end{tabular}

SD standard deviation, GLFS-25 the 25-Question Geriatric Locomotive Function Scale

indicated that weak abdominal trunk muscle strength, as measured by our device, was associated with decreased static balance and function, and increased risk of falling, regardless of CLBP.

The limitations of the present study include its small sample size and the inclusion of a significant portion of participants with other locomotive organ disorders, which may have affected the results. There was no correlation between abdominal trunk muscle strength and GLFS-25 scores because other locomotive organ disorders may have influenced the scores. The causes of CLBP in the study subjects were multifactorial and they were not examined. Muscle strength of the back and lower extremities was not measured, and spinal alignment was not analyzed. The correlation between abdominal trunk muscle strength and the strength of these muscles or spinal deformities was not evaluated in this study. In addition, extrinsic and environmental risk factors for falling were not obtained or evaluated in this study. Further studies with larger cohorts and that include men, are required to confirm the results of our study. Future studies involving older patients with CLBP and deteriorated physical ability are also needed to validate the efficacy of the device for the treatment of patients with CLBP and locomotive syndrome.

Despite its limitations, this study showed that the abdominal muscle strength of older patients with CLBP was significantly lower than that of subjects without CLBP, and that muscle strength weakness was associated with a history and risk of falling. Our device is a viable option for measuring abdominal muscle strength as a factor contributing to physical function.

\section{Conclusion}

We measured abdominal muscle strength in older women with CLBP using a novel device, and found that

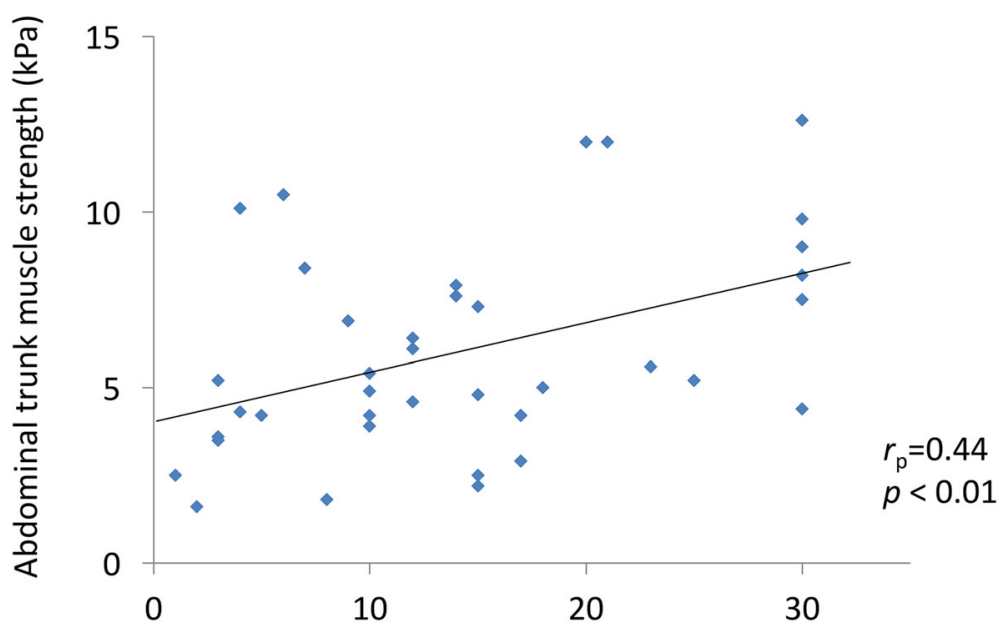

One-leg standing time with eyes open (second)

Fig. 3 Correlation between muscle strength values as measured by our device and one-leg standing time with eyes open 
Table 7 Correlation with the Abdominal trunk muscle strength measured by the device in the 21 patients of the LBP group

\begin{tabular}{llll}
\hline & Mean \pm SD & \multicolumn{2}{c}{ Correlations with abdominal trunk muscle strength } \\
\cline { 3 - 4 } & & $R_{p}$ value & $P$ value \\
\hline Abdominal trunk muscle strength measured by the device $(\mathrm{kPa})$ & $5.1 \pm 2.4$ & - & - \\
VAS for CLBP & $45.6 \pm 15.4$ & -0.15 & 0.52 \\
The dimensions of JOABPEQ & & & 0.07 \\
Scores for pain-related disorders & $64.6 \pm 27.6$ & 0.40 & 0.60 \\
Scores for lumbar spine dysfunction & $68.1 \pm 15.7$ & 0.12 & 0.50 \\
Scores for gait disturbance & $62.9 \pm 26.5$ & 0.16 & 0.13 \\
Scores for social life function & $62.8 \pm 14.1$ & -0.35 & -0.19 \\
Scores for psychological disorders & $52.6 \pm 14.0$ & -0.42 & \\
\hline
\end{tabular}

SD standard deviation, VAS visual analog scale, CLBP chronic low back pain, JOABPEQ the Japanese Orthopaedic Association Back Pain Evaluation Questionnaire

it was significantly lower than that of those without CLBP. Muscle weakness was associated with a history and risk of falling. Further studies are needed to validate the efficacy of our device for the treatment of CLBP and locomotive syndrome.

\section{Abbreviations}

CLBP: Chronic low back pain; GLFS-25: 25-Question Geriatric Locomotive Function Scale; JOABPEQ: Japanese Orthopaedic Association Back Pain Evaluation Questionnaire; LBP: Low back pain; VAS: Visual analog scale

\section{Acknowledgements}

Not applicable.

\section{Authors' contributions}

Research conception and design: SK, HM. Data collection: SK, SD, KY, KS, N Yokogawa, TI, N Yonezawa, TS. Interpretation of data: SK, SD, KY. Statistical analysis: SK, N Yokogawa, TI. Drafting the manuscript: SK. Manuscript review: HM, SD, HT. Study supervision: HM, HT. Approval of the final manuscript: all the above-listed authors.

\section{Funding}

The authors declare that they do not receive any funding concerning the study.

\section{Availability of data and materials}

The datasets during and/or analyzed during the current study are available from the corresponding author on reasonable request.

\section{Ethics approval and consent to participate}

The Kanazawa University ethics committee approved this study (Approval number: 1947). Written informed consent was obtained from each subject.

\section{Consent for publication}

Not applicable.

\section{Competing interests}

The authors declare that they have no competing interests.

Received: 13 December 2018 Accepted: 24 May 2019

Published online: 03 June 2019

\section{References}

1. Dagenais S, Caro J, Haldeman S. A systematic review of low back pain cost of illness studies in the United States and internationally. Spine J. 2008;8(1): 8-20.

2. Cassidy JD, Carroll $\sqcup$, Cote P. The Saskatchewan health and back pain survey. The prevalence of low back pain and related disability in Saskatchewan adults. Spine (Phila Pa 1976). 1998;23:1860-6.
3. Airaksinen O, Brox Jl, Cedraschi C, Hildebrandt J, Klaber-Moffett J, Kovacs F, et al. Chapter 4. European quidelines for the management of chronic nonspecific low back pain. Eur Spine J. 2006;15(suppl 2):S192-300.

4. Nakamura M, Nishiwaki $Y$, Ushida T, Toyama $Y$. Prevalence and characteristics of chronic musculoskeletal pain. J Orthop Sci. 2011;16:424-32.

5. Lee JH, Hoshino Y, Nakamura K, Kariya Y, Saita K, Ito K. Trunk muscle weakness as a risk factor for low back pain. A 5-year prospective study. Spine (Phila Pa 1976). 1999:24:54-7.

6. Cho KH, Beom JW, Lee TS, Lim JH, Lee TH, Yuk JH. Trunk muscles strength as a risk factor for nonspecific low back pain: a pilot study. Ann Rehabil Med. 2014;38:234-40.

7. Standaert CJ, Weinstein SM, Rumpeltes J. Evidence-informed management of chronic low back pain with lumbar stabilization exercises. Spine J. 2008;8: 114-20.

8. Mayer J, Mooney $\mathrm{V}$, Dagenais $\mathrm{S}$. Evidence-informed management of chronic low back pain with lumbar extensor strengthening exercises. Spine J. 2008; 8:96-113.

9. Oliveira CB, Maher CG, Pinto RZ, Traeger AC, Lin CC, Chenot JF, van Tulder $M$, Koes BW. Clinical practice guidelines for the management of non-specific low back pain in primary care: an updated overview. Eur Spine J. 2018;27: 2791-803.

10. Hayden JA, van Tulder MW, Tomlinson G. Systematic review: strategies for using exercise therapy to improve outcomes in chronic low back pain. Ann Intern Med. 2005;142:776-85.

11. Searle A, Spink M, Ho A, Chuter V. Exercise interventions for the treatment of chronic low back pain: a systematic review and meta-analysis of randomised controlled trials. Clin Rehabil. 2015;29:1155-67.

12. Rudy TE, Weiner DK, Lieber SJ, Slaboda J, Boston JR. The impact of chronic low back pain on older adults: a comparative study of patients and controls. Pain. 2007;131:293-301.

13. Coyle PC, Velasco T, Sions JM, Hicks GE. Lumbar mobility and performancebased function: an investigation in older adults with and without chronic low back pain. Pain Med. 2017:18:161-8.

14. Nakamura KA. 'Super-aged' society and the 'locomotive syndrome'. J Orthop Sci. 2008;13:1-2.

15. Arden NK, Crozier S, Smith H, Anderson F, Edwards C, Raphael H, et al. Knee pain, knee osteoarthritis, and the risk of fracture. Arthritis Rheum. 2006 Aug; 55:610-5.

16. Muraki S, Akune T, Oka H, Ishimoto Y, Nagata K, Yoshida M, et al. Physical performance, bone and joint diseases, and incidence of falls in Japanese men and women: a longitudinal cohort study. Osteoporos Int. 2013;24(2):459-66.

17. Nakamura K, Ogata T. Locomotive syndrome: definition and management. Clin Rev Bone Miner Metab. 2016;14:56-67.

18. Kato S, Murakami H, Inaki A, Mochizuki T, Demura S, Nakase J, et al. Innovative exercise device for the abdominal trunk muscle: an early validation study. PLoS One. 2017;12:e0172934.

19. Kato S, Kurokawa Y, Tsuchiya H. Development of innovative device for strengthening and strength measurement of the abdominal trunk muscles [in Japanese]. J Clin Sports Med. 2019;36:82-7.

20. Tinetti ME, Speechley M, Ginter SF. Risk factors for fall among elderly persons living in the community. N Engl J Med. 1988;319:1701-7. 
21. Vellas BJ, Wayne SJ, Romero L, Baumgartner RN, Rubenstein LZ, Garry PJ, One-leg balance is an important predictor of injurious falls in older persons. J Am Geriatr Soc. 1997;45:735-8.

22. Lundin H, Sääf M, Strender LE, Nyren S, Johansson SE, Salminen H. One-leg standing time and hip-fracture prediction. Osteoporos Int. 2014;25:1305-11.

23. Hashizume H, Konno S, Takeshita K, Fukui M, Takahashi K, Chiba K, et al. Japanese orthopaedic association back pain evaluation questionnaire (JOABPEQ) as an outcome measure for patients with low back pain: reference values in healthy volunteers. J Orthop Sci. 2015;20:264-80

24. Demura S, Yamada T, Uchiyama M, Sugiura H, Hamazaki H. Selection of useful items for fall risk screening for community dwelling Japanese elderly from the perspective of fall experience, physical function, and age level differences. Arch Gerontol Geriatr. 2011;53:123-30.

25. Bongue B, Dupré C, Beauchet O, Rossat A, Fantino B, Colvez A. A screening tool with five risk factors was developed for fall-risk prediction in community-dwelling elderly. J Clin Epidemiol. 2011;64:1152-60.

26. Helewa A, Goldsmith C, Smythe H, Gibson E. An evaluation of four different measures of abdominal muscle strength: patient, order and instrument variation. J Rheumatol. 1990;17:965-9.

27. Lee JH, Ooi Y, Nakamura K. Measurement of muscle strength of the trunk and the lower extremities in subjects with history of low back pain. Spine (Phila Pa 1976). 1995;20:1994-6.

28. Nourbakhsh MR, Arab AM. Relationship between mechanical factors and incidence of low back pain. J Orthop Sports Phys Ther. 2002;32:447-60.

29. Akuthota V, Ferreiro A, Moore T, Fredericson M. Core stability exercise principle. Curr Sports Med Rep. 2008:7:39-44

30. Granacher U, Gollhofer A, Hortobagyi T, Kressig RW, Muehlbauer T. The importance of trunk muscle strength for balance, functional performance, and fall prevention in seniors: a systematic review. Sports Med. 2013;43:627-41.

31. Granacher U, Lacroix A, Muehlbauer T, Roettger K, Gollhofer A. Effects of core instability strength training on trunk muscle strength, spinal mobility, dynamic balance and functional mobility in older adults. Gerontology. 2013; 59:105-13.

\section{Publisher's Note}

Springer Nature remains neutral with regard to jurisdictional claims in published maps and institutional affiliations.

Ready to submit your research? Choose BMC and benefit from:

- fast, convenient online submission

- thorough peer review by experienced researchers in your field

- rapid publication on acceptance

- support for research data, including large and complex data types

- gold Open Access which fosters wider collaboration and increased citations

- maximum visibility for your research: over $100 \mathrm{M}$ website views per year

At $\mathrm{BMC}$, research is always in progress.

Learn more biomedcentral.com/submissions 